\author{
Константинова Н. В.
}

\begin{abstract}
Аннотация. Цель исследования - выделить и охарактеризовать варианты беллетризации документального травелога, способы ориентации на прецедентные тексты как средство выражения субъективно-личностных установок пишущего субъекта. В статье на материале записок Е. А. Авдеевой («Записки и замечания о Сибири» и «Воспоминания об Иркутске») проясняется специфика особой авторской стратегии - женский взгляд на само путешествие и на способ его описания, выявляется механизм текстопорождения истории о путешествии с точки зрения «художественного сознания» автора, обосновывается правомерность исследования женской авторской стратегии в документальном травелоге на фоне литературной традиции (развития женского литературного творчества в период эмансипации). Научная новизна исследования заключается в изучении специфики женской авторской стратегии в русских документальных травелогах первой половины XIX века (на материале записок Е. А. Авдеевой). В результате доказано, что в женском документальном травелоге первой половины XIX века анализ способов беллетризации позволяет определить специфику «художественного сознания», имплицитную ориентацию писательницы-путешественницы на «феминистскую литературу» этого периода.
\end{abstract}

\title{
EN Specifics of "Artistic Consciousness" in Female Travelogue of the First Half of the XIX Century (Based on the Notes of E. A. Avdeeva)
}

\author{
Konstantinova N. V.
}

\begin{abstract}
The aim of the research is to highlight and characterize the variants of fictionalization of documentary travelogue, the methods of orientation towards precedent texts as a means of expressing the subjective and personal attitudes of the writing subject. The article, based on the notes of E. A. Avdeeva ("Notes and Remarks about Siberia" and "Memories of Irkutsk"), clarifies the specificity of the author's special strategy a woman's view of the journey itself and the way of describing it, reveals the mechanism of text generation of a story about a journey from the point of view of the author's "artistic consciousness"; the researcher substantiates the legitimacy of studying the female author's strategy in documentary travelogue against the background of the literary tradition (the development of female literary creativity during the period of emancipation). The scientific novelty of the research lies in studying the specificity of the female author's strategy in Russian documentary travelogues of the first half of the XIX century (based on the notes of E. A. Avdeeva). As a result, it was proved that in female documentary travelogue of the first half of the XIX century, an analysis of the methods of fictionalization makes it possible to determine the specifics of the "artistic consciousness", the implicit orientation of the travel writer towards the "feminist literature" of this period.
\end{abstract}

\section{Введение}

Актуальность темы исследования обусловлена тем, что в контексте эволюции жанра травелога в первой половине XIX века произведения писательниц-путешественниц наиболее репрезентативно представляют индивидуально авторские нарративные стратегии, способы конструирования творческого субъекта, варианты беллетризации документального травелога как способы выражения «художественного сознания» автора. Анализ представленных произведений с этой точки зрения позволяет также сделать важные выводы об основных тенденциях развития жанра в первой половине XIX веке и на фоне литературной традиции (развития женского

Научная статья (original research article) | https://doi.org/10.30853/phil20210650

(๔) 2021 Авторы. 000 Издательство «Грамота» (๔ 2021 The Authors. GRAMOTA Publishers). Открытый доступ предоставляется на условиях лицензии СС ВY 4.0 (open access article under the CС BY 4.0 license): https://creativecommons.org/licenses/by/4.0/ 
литературного творчества в период эмансипации). Характерной особенностью женских травелогов этого периода становится ориентация не только на популярную карамзинскую традицию, но и на контекст женской литературной прозы. В связи с этим вопрос о специфике «художественного сознания» в женских травелогах XIX века является актуальным как при изучении проблемы автора в русском документальном травелоге XIX века, так и в контексте исследования эволюции женской прозы, а именно гендерных аспектов феномена авторства.

Для достижения указанной цели исследования необходимо решить следующие задачи: во-первых, прояснить специфику особой авторской стратегии - женский взгляд на само путешествие и на способ его описания; во-вторых, выявить механизм текстопорождения истории о путешествии с точки зрения «художественного сознания» автора; в-третьих, обосновать правомерность исследования женской авторской стратегии в документальном травелоге на фоне литературной традиции (развития женского литературного творчества в период эмансипации). Для осмысления специфики «художественного сознания» в женских травелогах XIX века в статье применяются следующие методы исследования: структурно-семиотический и герменевтико-интерпретационный. С помощью системного подхода обеспечивается аналитическое описание вариантов беллетризации в женских документальных травелогах XIX века.

Теоретической базой исследования послужили публикации И. Л. Савкиной (1998; 2007), Э. Шоре (2000), Е. Н. Строгановой (Русская литература..., 2004), А. Белецкого (1923), в которых рассматриваются особенности женской прозы XIX века, выделяются жанровые модификации, основные тенденции развития женского литературного творчества в период эмансипации. Кроме того, в работе использовано исследование Е. Г. Милюгиной и М. В. Строганова (2016) о специфике тверских травелогов, в которых наблюдается характеристика женских путевых записок. Практическая значимость исследования заключается в том, что раскрываемый в статье принцип выражения художественного сознания в женских документальных травелогах первой половины XIX века (на материале записок Е. А. Авдеевой) может быть использован в педагогической деятельности для усовершенствования образовательного процесса в курсах теории литературы и истории русской литературы XIX в.

\section{Основная часть}

В современном литературоведении все чаще появляются гендерные исследования, в которых наблюдается интерес к интерпретации женского письма. В качестве примера можно назвать коллективное исследование «Русская литература XIX века в гендерном измерении» (2004) и монографию И. Л. Савкиной «Провинциалки русской литературы (женская проза 30-40-х годов XIX века)» (1998). В последней работе отмечается, что «в 30-40-е годы наряду с многочисленными журнальными публикациями и женскими книгами появляются критические статьи, которые не только комплементарно упоминают женские имена или представляют отдельные произведения, но и вводят в культурный обиход новое понятие или, точнее сказать, новый дискурс - женская литература» (с. 6). Об этом рассуждает и А. Белецкий (1923), отмечая, что в эти годы (30-60-е) «критика охотно обсуждала вопросы о том, должны или не должны писать женщины, и какова область, где женское дарование может развернуться в полной силе, искали специфических примет и особенностей женского творчества» (с. 141).

При этом изучению специфики женского авторского начала в жанре травелога не уделяется особого внимания, в большей степени привлекают исследователей романное повествование и поэтические жанры. Безусловно, это объясняется непопулярностью жанра травелога в женской литературе. Однако именно в таких текстах, на наш взгляд, в большей степени проявляется специфика индивидуально-авторской стратегии. Особое место в этом отношении занимают документальные травелоги, которые демонстрируют в начале XIX века очевидную зависимость от карамзинской традиции, представляя различные комбинации литературных приемов, способов беллетризации. Например, в статье Е. Г. Милюгиной и М. В. Строганова «Травелог как документальный жанр» (2016) отмечается: «Еще большим наступлением на документальность травелога является его беллетризация. Так, А. И. Ишимова в построении своего травелога (1844) руководствуется не пространственными параметрами описываемого места и не логикой реального маршрута, а литературным сюжетом, развитие которого определяют поступки и переживания героев» (с. 251). Подобный комментарий исследователей обнаруживает в путевых записках А. И. Ишимовой очевидный прием беллетризации, благодаря которому в документальном травелоге выражается сознательная установка писательницы-путешественницы на художественность, на решение эстетических задач.

Таким образом, безусловно, даже в документальных травелогах наблюдается очевидное соединение объективного (описательно-очеркового) и субъективного (эмоционального и аналитико-идеологического) аспектов повествования, что и становится одним из способов выражения «художественного сознания» автора-путешественника.

Наиболее репрезентативным текстом в данном отношении, на наш взгляд, являются «Записки и замечания о Сибири» Е. А. Авдеевой, опубликованные в 1837 году. Особенность этого травелога заключается в том, что заявленные в предисловии авторские установки очевидно нарушаются в повествовании о путешествии. В большей степени это выражается в том, что автор позиционирует себя как объективного повествователя о событии путешествия, который не ориентируется ни на какую литературную традицию. В то же время в текстах обнаруживаются имплицитные (в большей или меньшей степени) отсылки к литературным произведениям, которые и выражают специфику «художественного сознания» автора.

Так, например, описывая сибирские обычаи в книге «Записки и замечания о Сибири», Е. А. Авдеева одна из первых ведет свое повествование в жанре записок, вкрапляя в текст множество разнообразных сведений, 
давая словарь местных речений, включая значительное собрание народных песен - этот своеобразный и богатый материал служит дополнением к эпизодам и картинам жизни в Сибири начала XIX века.

Как можно заметить, уже в предисловии издателя прокомментировано, что «Записки и замечания о Сибири» (Авдеева, 1837) демонстрируют именно специфику женского сознания: «Но в предлагаемой читателю книге, он, после нескольких страниц, убедится, что ее писала женщина, и даже не светская, не имеющая никаких притязаний на авторство. Скажу больше: я имел поручение дополнить и даже переправить эту книгу, но я не сделал этого, и она перед глазами читателя в том виде, в каком вышла из-под пера сочинительницы» (с. 4). Эта установка выражается не только в авторской номинации, но и в самой манере письма («как он описан»). При этом издатель, брат писательницы Ксенофонт Полевой, акцентирует внимание на отсутствии претензий женщины-сочинительницы на авторство, чем в первую очередь противопоставляет ее популярным в это время писательницам светского типа, пытающимся получить признательность публики, ориентируясь на шаблоны и стереотипы (как он их называет, «пошлые литературные приличия»).

Таким образом, путевые записки Е. А. Авдеевой позиционируются как особый самобытный тип женского сочинения, не имеющего аналогов ни в женской литературной прозе XIX века, ни тем более в традиции развития жанра травелога, демонстрируют установку на документальность и достоверность материала, противопоставление таких категорий, как образованность/ученость, простота/искренность/непосредственность восприятия. Безусловно, такого рода стратегии самоуничижения автора, который не претендует на создание литературного произведения высокого уровня, заранее извиняется перед читателями, встречалась и в других травелогах XIX века (военных, морских, например). Е. А. Авдеева (1837) же, с одной стороны, настаивает на объективности своего повествования, предельной документальности, но тут же комментирует: «мне приятно вспомнить», что свидетельствует о наличии чувствительного, эмоционального аспекта: «С удовольствием слышу я, что многие образованные люди пишут о разных частях Сибири. Чтобы описать всю Сибирь, ее произведения, народы, населяющие ее, их обряды, предания, надобно посвятить на это жизнь свою. Я буду, напротив, говорить только о том, что видела, и не с тем, чтоб попасть в число писательниц. Мне приятно вспомнить о той стране, где прошли лета моей молодости» (с. 7).

Однако такая установка автора не в полной мере реализуется в этом тексте о Сибири. В процессе чтения записок становится очевидной стратегия, выраженная в намеренном конструировании определенного типа героя, точнее героини, а именно в создании образа просвещенной, самостоятельной, начитанной женщины (что соответствует популярному в этот период типу эмансипированной женщины, транслируемому в женской литературе). При этом хотелось бы отметить определенные приемы создания этого образа в записках Е. А. Авдеевой, которые, конечно, выражаются как способы беллетризации травелога.

Так, например, позиционируя себя как объективного повествователя, бытописателя, этнографа, писательница все же неоднократно высказывает различные предложения, с помощью которых она хотела бы изменить жизнь в этой местности в лучшую сторону: «Очень было бы приятно, если бы иркутские капиталисты, согласясь между собою, устроили пансион для воспитания девиц, тем более, что вообще многие имеют способности и склонность к учению и стараются недостаток воспитания вознаградить чтением книг» (Авдеева, 1837, с. 54).

Кроме того, интересно, что в процессе описания старинных сибирских обрядов и обычаев сочинительница, представляя себя такой же любительницей старины, в то же время ориентируется на классический литературный шаблон. Но при этом в описании главной героини, которую она открыто сравнивает со Светланой из баллады В. А. Жуковского, автор указывает ее главные качества, характерные для нового литературного женского типа: «Вот что рассказывала мне одна очень умная и без всяких предрассудков девушка. Вздумала она смотреть в зеркало ночью. Дом, где жила она, был большой, каменный в два этажа. Взявши с собой девушку, она велела ей лечь спать в ближней комнате, а сама села перед зеркалом. Была полночь. Она сидит, как Светлана, ждет появления суженого; все в доме спят, и ворота заперты; внизу у дверей был колокольчик...» (Авдеева, 1837, с. 64). В этой истории имплицитно соотносится эмансипированная героиня женской прозы с классическим литературным образом. При этом фольклорная основа истории становится материалом для изображения принципиально иного женского сознания, рационального, свободного от предрассудков.

Таким образом, очевидно поэтизируя рассказы о сибирских народных обычаях, выражая свою эмоциональную причастность, Е. А. Авдеева (1837) все же настаивает на их другой оценке, демонстрирует точку зрения уже не любительницы «милой старины», а просвещенной женщины: «Я не хочу хвалить старых обычаев и суеверий, но, кажется, все они доказывают простоту нравов. Желаю от чистого сердца, чтоб все эти пустяки заменились истинным просвещением, а не модным обезьянством, которое ни в каком случае не ведет к добру» (с. 67).

Кроме того, в более позднем тексте писательницы - «Воспоминаниях об Иркутске» (1848) - очевидные приемы беллетризации обнаруживаются и в документальных историях о выдающихся жителях Сибири. Пытаясь объективно описывать биографии замечательных людей, писательница все же выделяет в них очевидно сентиментальные или романтические сюжеты (о несчастной любви, например). Так, подробно характеризуя жизненный путь Сомова, Е. А. Авдеева представляет его через призму трагической любовной истории: «Вообще он имел голову романическую, задумчивое лицо и чрезвычайно нравился женщинам. Находясь в светском кругу, он переходил от одного успеха к другому, но наконец в сердце его вспыхнула истинная страсть к одной богатой и знатной девице. <...> Может быть, и у этой девицы была также романическая голова, и потому желала, чтоб он как рыцарь доказал ей свою любовь и заслужил ее руку военными подвигами» (с. 26). При этом в характеристике поведения и состояния своего героя - реального исторического лица - писательница 
акцентирует внимание не столько на индивидуальных качествах личности Сомова, а на особенностях, которые соотносят его образ с литературным шаблоном. Так, например, финал этой любовной истории очевидно выражает стратегии поведения сентиментального героя: «По приезде в Москву Сомов спешил в дом милой сердцу его и узнал, что она уже замужем!.. Можно представить себе тоску и грусть человека истинно чувствительного... Никогда не мог он утешиться в этом разрушении всех планов своего счастья и едва не впал в меланхолию» (с. 26). И вся собственно документальная биографическая часть при этом уходит на второй план, становится не столь значительной, превращается в некий второстепенный фоновый материал для описания «литературного сюжета».

Кроме подобных приемов выражения «художественного сознания», на наш взгляд, достаточно типичных для документальных травелогов первой половины XIX века, именно в этих записках Е. А. Авдеевой встречается фрагмент, который в большей степени характеризует специфику субъективного аспекта повествования: в нем обнаруживается неожиданное соединение основных авторских задач - любовь и внимание к сибирской старине, к ее самобытности, ощущение личной сопричастности, желание сохранить образцы народной культуры для нового поколения, а также просветительские цели - акцентировать внимание на ценности просвещения и образования для женщин, желании изменить их способ существования (сочетание древних исконно русских и современных европейских традиций). В рассказе о местном топонимическом предании про Царь-Девицу выражаются основные клишированные черты женского типа героини, популярного в беллетристике этого периода. Отметим основные характеристики фольклорного образа, которые соотносятся с литературной традицией женской прозы XIX века.

Так называемая «феминистская проза» формирует представление о сильной независимой женщине, которая самостоятельно решает жизненные проблемы. В рассказе о Царь-Девице Е. А. Авдеева (1848) акцентирует внимание на таких особенностях главной героини предания: «На левом берегу Ангары, против города, есть место, называемое Царь-Девица. <...> Лет сто назад приехала туда, неизвестно откуда, девица высокого роста, красивая и, как видно, очень неустрашимая, потому что она одна-одинехонька поселилась на этом месте, построила там себе избушку, обнесенную частым тыном, держала злых собак и не пускала к себе никого. Она сама работала в своем огороде, а для необходимых пособий в работе и для посылок в город прихаживала к ней старуха-поселыцица. Она-то рассказывала про нее, какая она умница и разумница, как она то работает в огороде, то сидит за книгами, а как заговорит о чем, то будто сладким медом поит» (с. 31). В этом фрагменте обращает на себя внимание и другая «общая черта» эмансипированной героини женской прозы высокий уровень образованности, стремление к чтению книг, просвещенность. Царь-Девица становится известной также благодаря своему уму и способности давать мудрые советы: «Она провела много лет таким образом и в старости своей допускала к себе некоторых из иркутских жителей, которые являлись просить совета у нее в трудных случаях и возвращались в восторге от ее ума и красноречия. Она умерла, оставшись неизвестною, так что никто не знал ни имени, ни происхождения ее, но за мудрость и чистое поведение прозвали ее Царь-Девицей» (с. 32). Таким образом, фольклорное предание в записках Е. А. Авдеевой превращается в подобие литературного сюжета об эмансипированной героине.

Как отмечает в своем исследовании Э. Шорэ (2000), пример Жорж Санд и героинь ее романов побудил многих женщин из общества порвать цепи семейных и супружеских уз, вырваться из узких рамок семейных отношений для достижения прав женского индивидуума и «свободы чувств». В России «первой русской феминисткой» традиционно называют Елену Ган (2011), которая одна из первых затронула тему равноправия женщин в литературных произведениях. Так, например, в ее повести «Идеал» создается женский тип героини, которая отличается начитанностью, «высшим умом», образованностью, благородством, что приводит к разочарованию в обществе, любви, к идее самоизоляции от внешнего мира: «Самый тесный эгоизм - вот моя стезя. Я не могу любить моею первою, чистою любовью и не хочу предаваться никакому чувству второстепенному; и потому никогда не выйду замуж. Я покину мир, как покидает пришлец чужую сторону, где он принужден был говорить языком других и считал свое пребывание только чужими обедами» (с. 69).

Подобные идеи все чаще становятся ключевым элементом такого типа героини и в беллетристике 50-х годов XIX века, воплощаются в большей степени в произведениях Н. Николаенко (Н. Д. Шамониной) (1858), А. Я. Панаевой (1849). Кроме того, такой способ существования просвещенной эмансипированной женщины все больше переносится и в биографическую жизнь писательниц. Так, и жизнеописание самой Е. А. Авдеевой, представленное в изложении ее брата Николая Полевого в тексте «Записки о старом и новом быте» (1842), можно сравнить с таким типом литературной героини: «В том заключалось все ее образование, но как ничтожны кажутся мне иногда хвастливая образованность ученых женщин и односторонняя схоластика педантов перед образованием и ученостью этой необыкновенной женщины, когда притом никто и не подумал бы, видя ее, под ее простыми, не светскими формами искать и найти обширное просвещение при уме самобытном. <...> Только одиночество жизни в летах преклонных заставило ее однажды решиться изложить свои воспоминания о Сибири. <...> Добродушная сочинительница не позволила выставить в заглавие своего имени» (с. 4). Самобытный ум, одиночество, стремление к самоизоляции, отсутствие «светских» претензий на сочинительство очевидным образом соотносят образ автора травелога с литературным типом, популярным в период эмансипации. В одной из своих работ, посвященных женскому письму, И. Л. Савкина (2007) отмечает: «Автодокументальные жанры - письма, дневники, воспоминания и т. п. - это своего рода разговоры с зеркалом, со своим другим Я, отчужденным и возвращенным себе. Женщины пишут, осуществляясь 
в акте письма; увидев себя в зеркале и Зазеркалье автотекста, они воссоздают себя, утверждая: “я есть, я пишу, значит - существую”» (с. 2). Таким образом, травелоги Е. А. Авдеевой становятся своего рода зеркалом ее имплицитного представления о себе и о своем женском идеале.

В своих текстах Е. А. Авдеева и миссию автора определяет как просветительскую деятельность. В то же время в нарративных стратегиях ее записок наблюдается явно сочетание разнородных точек зрения: путешественника-историка-этнографа, фольклориста, патриота и исследователя, сентиментального путешественника, женщины чувствительной и эмоционально зависимой от собственных интересов и пристрастий, литературных и общественных тенденций. При этом «внутренним сюжетом» записок становится характеристика современного ей женского Идеала, выраженного в наборе клишированных сюжетных ситуаций (изоляция от общества, самостоятельность, отказ от общепринятых ценностей) и характеристик (умная, просвещенная, начитанная).

\section{Заключение}

Таким образом, мы приходим к следующим выводам. На материале записок Е. А. Авдеевой наиболее репрезентативно выражается специфика «художественного сознания» автора документального травелога. Благодаря анализу вариантов беллетризации в документальном травелоге выделяются способы ориентации на прецедентные тексты как средство выражения субъективно-личностных установок пишущего субъекта, что в женских травелогах позволило обнаружить связь с «феминистской прозой» первой половины XIX века.

Перспективы дальнейшего исследования проблемы мы видим в более детальном изучении способов беллетризации в женских травелогах XIX века, выделении общих нарративных тенденций и индивидуальных авторских стратегий.

\section{Источники | References}

1. Авдеева Е. А. Воспоминания об Иркутске // Отечественные записки. 1848. Т. 58. № 5. Отд. 8.

2. Авдеева Е. А. Записки и замечания о Сибири. М., 1837.

3. Авдеева Е. А. Записки о старом и новом русском быте. СПб.: Тип. Штаба воен.-учеб. заведений, 1842.

4. Белецкий А. Тургенев и русские писательницы 30-60-х гг. // Творческий путь Тургенева: сб. ст. / под ред. Н. Л. Бродского. Петроград: Сеятель, 1923.

5. Ган Е. А. Идеал. М.: Директ-Медиа, 2011.

6. Милюгина Е. Г., Строганов М. В. Травелог как документальный жанр. Статья первая // Русский травелог XVIII-XX веков: маршруты, топосы, жанры и нарративы / под ред. Т. И. Печерской, Н. В. Константиновой. Новосибирск: Изд-во НГПУ, 2016.

7. Николаенко Н. (Шамонина Н. Д.) Чудачка // Русский вестник. 1858. Т. 18.

8. Панаева А. Я. Пасека // Современник. 1849. Т. 18.

9. Русская литература XIX века в гендерном измерении: опыт коллективного исследования / науч. ред. Е. Н. Строганова. Тверь: Лилия Принт, 2004.

10. Савкина И. Л. Провинциалки русской литературы (женская проза 30-40-х годов XIX века). Wilhelmshorst: Verlag F. K. Gopfert, 1998.

11. Савкина И. Л. Разговоры с зеркалом и зазеркальем. Автодокументальные женские тексты в русской литературе первой половины ХІХ века. М.: Новое литературное обозрение, 2007.

12. Шоре Э. Елена Ган - русская Жорж Санд? // Пол. Гендер. Культура: немецкие и русские исследования. М., 2000. Вып. 2 / под ред. Э. Шоре, К. Хайдер, Г. Зверевой.

\section{Информация об авторах | Author information}

RU Константинова Наталья Владимировна ${ }^{1}$, к. филол. н., доц.

${ }^{1}$ Новосибирский государственный педагогический университет

EN Konstantinova Natalya Vladimirovna ${ }^{1}, \mathrm{PhD}$

${ }^{1}$ Novosibirsk State Pedagogical University

${ }^{1}$ scribe2@yandex.ru

\section{Информация о статье | About this article}

Дата поступления рукописи (received): 14.11.2021; опубликовано (published): 28.12.2021.

Ключевые слова (keywords): беллетризация; травелог; женская авторская стратегия; художественное сознание автора; Е. А. Авдеева; fictionalization; travelogue; female author's strategy; author's artistic consciousness; E. A. Avdeeva. 